\title{
A mixed-methods evaluation of a cluster randomized controlled trial on simulation-based low-dose, high- frequency plus mobile mentoring training versus traditional group-based training of health workers in Ebonyi and Kogi States, Nigeria
}

EMMANUEL UGWA ( $\nabla$ Emmanuel.Ugwa@jhpiego.org )

$$
\begin{aligned}
& \text { JHPIEGO } \\
& \text { Mark Kabue }
\end{aligned}
$$

JHPIEGO

Emmanuel Otolorin

JHPIEGO

\section{Gayane Yenokyan}

Johns Hopkins University School of Public Health

Adetiloye Oniyire

JHPIEGO

Bright Orji

JHPIEGO

Ugo Okoli

JHPIEGO

Joseph Enne

JHPIEGO

Gabriel Alobo

JHPIEGO

Gladys Olisaekee

JHPIEGO

Oluwatobi Adebayo

JHPIEGO

Chioma Oduenyi

JHPIEGO

Adekunle Aledare

$\mathrm{MoH}$, Kogi State

Boniface Onwe

$\mathrm{MoH}$, Ebonyi State

Gbenga Ishola

JHPIEGO 


\section{Research article}

Keywords: training, simulation, mentoring, health workers, maternal and child health, Nigeria

Posted Date: November 9th, 2019

DOl: https://doi.org/10.21203/rs.2.17089/v1

License: (a) (i) This work is licensed under a Creative Commons Attribution 4.0 International License. Read Full License 


\section{Abstract}

Background: There are few studies from low- and middle-income countries on learning outcomes among health workers who have been trained on day of birth care using onsite, simulation-based, low-dose, high frequency (LDHF) training plus mobile $(\mathrm{m})$ mentoring. The aim of this study was to compare their knowledge and skills competencies with those of health workers trained using the traditional offsite, group-based training (TRAD) approach in Kogi and Ebonyi states, Nigeria, over a 12-month period. Methods: We conducted a prospective cluster randomized controlled trial, enrolling 299 health workers in 60 health facilities in Kogi and Ebonyi states, randomized to either LDHF/m-mentoring (intervention, $n=30$ facilities) or traditional groupbased training (TRAD, $n=30$ facilities) control arm. Health workers in both arms received basic emergency obstetric and newborn care training with simulated practice using anatomic models and role-plays. The control arm participants were trained offsite while the intervention arm were trained onsite where they work. Mentorship was done through telephone calls and reminder text messages. The multiple choice questions and objective structured clinical examinations mean scores were compared; $p$-value $<0.05$ was considered statistically significant. Qualitative data were collected and analyzed along themes of interest. Results: The mean knowledge scores between the two arms at months 3 and 12 post-training were equally high; no statistically significant differences. Both arms showed improvements in composite scores for assessed BEmONC clinical skills from around $30 \%$ at baseline to $75 \%$ and above at endline $(p<0.05)$. Overall, the observed improvement and retention of skills was higher in intervention arm compared to the control arm at 12 months post-training, $(\mathrm{p}<0.05)$. Some LDHF/m-mentoring approach trainees reported that mentors' support improved their acquisition and maintenance of knowledge and skills, which may have led to reductions in maternal and newborn deaths in their facilities. Conclusion: The LDHF/m-mentoring intervention is more effective than TRAD approach in improving health workers' skills acquisition and retention. Health care managers should have the option to select the LDHF/m-mentoring learning approach, depending on their country's priorities or context, as it ensures health workers remain in their place of work during training events thus less disruption to service delivery.

\section{Background}

Trainings of health workers in Nigeria commonly adopt the traditional lecture-based, offsite approach with a limited number participants from any health facility at a time. This training method can be expensive cost wise and in terms of interrupting service deliver when health workers are absent from their workstations for long duration [1-4]. The rising rates at which health workers are absent from work to attend offsite training is a concern for health facility managers $[3,4]$. Besides, the few numbers of health workers who can be trained in at a particular time thus only a few of them can benefit from the through these training updates and ultimately, the quality of care may not be improved to the desired level [2]. After the offsite training, the healthcare workers may be unable to practice new or updated skills because the entire team members have not been trained. Therefore, step-down training by those that were trained upon return to their place of work most often does not happen as intended due to lack of will and management support among other factors. This may present a barrier to the practice of new or updated skills by the health workers who received training. Moreover when there are health workers turnover and attrition over time as well as movement to other sectors, the 
quality of care provided remains poor if they involved those who received training. Consequently, maternal and newborn health outcomes have remained suboptimal despite trainings [2].

There are few studies from low- and middle-income countries (LMICs) on learning outcomes and facilitators and barriers to learning approaches on day-of-birth care among maternal and newborn health workers trained using onsite simulation-based low-dose, high-frequency (LDHF) plus mobile (m)-mentoring training approach compared to those trained by offsite traditional group-based training (TRAD). The LDHF/m-mentoring approach is described in the study protocol manuscript; it differ from the TRAD approach primarily by being onsite, more interactive, and team-oriented thus more suited to meet the needs of the trainees in various contextual situations [5]. The LDHF/m-mentoring approach also uses mobile phone mentorship calls and reminder text messages to the trainees.

There are low numbers and quality of skilled birth attendants in Nigeria. Therefore evidence-based approach is needed to train health workers to improve competencies and maternal/newborn outcomes [6,7]. Doctors, nurses and community health extension workers (CHEWs) are commonly trained on day of birth care. The CHEWs as a result of task sharing in Nigeria are also trained and posted to primary health centers with or without nurses. The training of CHEWs did not originally involve training on day of birth care at maternity. They should be able to initiate life-saving procedures if they are trained on basic emergency obstetric and newborn care (BEmONC) functions such as management of bleeding after birth and newborn resuscitation.

Considering the high maternal and newborn mortality and morbidity figures in Nigeria, there is need to train birth attendants on high-impact interventions using competency-based approaches to improve the quality of maternal and newborn care and reduce maternal and perinatal/neonatal mortality [8-11].

There is limited evidence from developing countries including Nigeria on facilitators, barriers, and effectiveness of simulation-based LDHF/m-mentoring learning approaches in improving maternal and newborn health, including day of birth care. In the few studies where the LDHF/m-mentoring approach has been tested, there sample sizes have been limited and methodological approaches have not been standardized [7]. it is therefore for research on capacity building of workers to incorporate in their designs culturally appropriate and effective techniques to improve the competencies health workers. The studies should be adequately powered and use rigorous designs to answer the research questions [7].

\section{Methods}

\section{Study Objectives}

The aim of this study was to compare the knowledge and skills competencies of providers who attended training in LDHF/m-mentoring with TRAD approaches in improving maternal and newborn care on the day of birth in Ebonyi and Kogi states, Nigeria. The study's primary outcomes were increase in knowledge, clinical skills in BEmONC, and retention of clinical competency at 3- and 12-months post-training. The secondary outcomes measured were facilitators of and barriers to the LDHF/m-mentoring training approach at individual and institutional levels. 
Our hypothesis was that LDHF/m-mentoring results in better knowledge and skills outcomes compared to the TRAD approach. The study was designed to answer three research questions:

1. How do knowledge learning outcomes of skilled birth attendants (SBA) in Kogi and Ebonyi states who were exposed to simulation-based LDHF/m-mentoring training approach differ from those exposed to TRAD approaches over 12 months?

2. How do skills learning outcomes of skilled birth attendants in Kogi and Ebonyi states who were exposed to simulation-based LDHF/m-mentoring training approaches differ from those exposed to TRAD approaches over 12 months?

3. What are the facilitators of and barriers to the LDHF/m-mentoring training approach at individual and institutional levels?

\section{Study setting}

Nigeria, with a population of 185.7 million as of 2017 (according to Nigeria Bureau of Statistics), has six geopolitical zones and 36 states plus the Federal Capital Territory (FCT). The study was conducted in two states: Ebonyi state has a population of 2.8 million and is in the South-East zone; Kogi state has a population of 4.3 million and is in the North-Central zone [5]. At the time of the study, the Maternal and Child Survival Program (MCSP), in partnership with the Federal Ministry of Health, Ebonyi and Kogi States Ministries of Health and Professional Associations supported 120 health facilities across the two states, of which 60 were selected to be part of the study, 30 in each state. The MCSP is a global, $\$ 560$ million, 5-year cooperative agreement funded by the United States Agency for International Development (USAID) to introduce and support scale-up of high-impact health interventions among USAID's 25 maternal and child health priority countries, as well as other countries.

\section{Study design}

This mixed-methods study used a prospective cluster randomized controlled trial design and qualitative methods that included focus group discussions (FGDs) and in-depth interviews (IDIs). The 60 health facilities were randomly selected and assigned to either the intervention arm or the control arm as described in the study protocol [5]. Trained assessors with a clinical background training administered questionnaires for knowledge test, observation checklists for the objective structured clinical examinations (OSCEs). Additionally, IDIs, and FGDs were used for qualitative data collection. BEmONC training packages were adapted from previous studies and training documents $[1,2]$. The tools were pre-tested among 25 health workers from health facilities that were not part of the study. Before being used, checklists for the assessed clinical skills were modified in accordance with the Nigeria context by the research team and data collectors. At the time of the study, MCSP did not support any interventions in these facilities that are likely to cause contamination. Other quality improvement interventions only happened at the non-study facilities at the time of the study. 
The details of the study methodology, including training approaches in the two study arms have been extensively described below and in the study protocol [5]. In brief, for both study arms, independent assessors who were blinded to the training approaches used did skills and knowledge assessments. The assessors underwent a 5-day clinical skills standardization training. Training of trainers was also done.

\section{Eligibility criteria}

Health facilities: selection of health facilities was based on a sampling frame of the 120 facilities supported by MCSP in the two states across all three geopolitical zones per state and included all three levels of health care delivery, primary (primary health care/private), secondary (general/missions), and tertiary.

Health workers: individual study participants were drawn from among those attending to women during labor and delivery in the selected health facilities in the two states. Participating health workers included doctors, nurses, midwives, and community health extension workers. Selected health workers were those who had spent at least six months in the health facility providing maternal and/or newborn care services and were available to participate in the trainings from the beginning to the end of the study (a 12-month period).

\section{Randomization}

The unit of randomization was the health facility. The 60 facilities were divided into nine strata by three geopolitical zones and by the level of health facility. Each stratum was randomized to either control or intervention arm using randomly permuted blocks in a ratio of 1:1 to achieve balance in the type of facility and location for each study arm. Health facilities were matched based on locations and levels of care prior to randomization and grouped as either receiving LDHF/m-mentoring or TRAD intervention. As there are, few skilled birth attendants in some health facilities, all health workers employed in the maternity or newborn units in such facilities who met the inclusion criteria were selected from the randomized health care facilities.

\section{Training approach 1 and data collection: Simulation-based LDHF/m-mentoring training of participants - group 1 or intervention group}

The training for the LDHF/m-mentoring arm was for the entire team of service providers available at the health facility, but only those who met the study inclusion criteria were assessed. After consent was obtained, the participants completed pre-training assessments consisting of MCQs and OSCEs done through use of anatomical models, to assess their baseline knowledge and skills in BEmONC. The MCQ test comprised a set questions to test trainees' knowledge while OSCEs were used to assess skills competency. The assessments tested their knowledge and skills on conduct of normal delivery, active management of the third stage of labor (AMTSL), neonatal resuscitation, case management of pre-eclampsia and eclampsia (PEE) and management of PPH (e.g. manual removal of placenta, internal bimanual uterine compression and compression of the abdominal aorta). The training was divided into two "low-dose" training courses of four days each, and 
included additional time for assessment as needed and was conducted at the health facilities using the adapted $\mathrm{BEmONC}$ training package repeated after 1 month. The training techniques were modified to focus more onpractice. Time spent on lectures was reduced and additional time spent on hands-on practice. Peer Practice Coordinators (PPCs) were selected from among the trainees. These are people who had shown exceptional interest on the course and had received technical update in LDHF including the use of session plans, case scenario and MamaNatalie/NeoNatalie models to conduct simulation practices. At the end of the four-day training, the participants underwent an immediate post-training assessment, which included MCQs and OSCEs. The questions answered correctly, and procedures done competently were scored over a total of $100 \%$. A test score of $\geq 80 \%$ is accepted as level of competence. During the one-month intervals between training courses, health care providers had the opportunity to practice what they learned and reinforced their competencies through high-frequency simulation-based practices of 2-3 times per week. The PPCs completed the practice logs and submitted them to the study coordinator. In addition to the simulation exercises, all the trained providers in the LDHF arm participated in mobile Mentoring, , which consisted of receiving weekly reminder messages and quizzes on the topics reviewed via SMS.. Also, the PPCs received structured, monthly half-hour mentoring calls from a trainer/master mentor that provide remote support, answering questions, providing guidance and reinforcing key messages. Skills and knowledge assessments were done at three time points post-training (immediate post training day, at three months 12 months). Trainees' satisfaction with the simulation-based LDHF/m-mentoring training approach will also be determined using satisfaction (quantitative) survey (5).

Qualitative data were collected through six focus group discussions (FGDs) comprising 8-10 participants per group who were purposively selected from among the trainees at 12 months. The FGDs focused on experiences and level of satisfaction of trainees with LDHF/m-mentoring training approach, the highfrequency practice sessions with simulators, mobile mentoring through SMS and quizzes, opinions about changes in clinical practice and outcomes and overall impressions of the LDHF/m-mentoring approach and what could be improved. Each FGD lasted 60-90 minutes. In-depth interviews were also conducted with PPCs and trainers at 12 months post-training by study staff. Additionally, IDIs were conducted among PPCs aimed

at elucidating their insights and experience managing simulator practice sessions for their facility, interacting and working with the trainers/master mentors, m-mentoring, changes in clinical practice and outcomes, success and challenges and overall impression about LDHF approach. For the trainers, their thoughts and experience with the LDHF/m-mentoring training approach, successes and challenges with mobile mentoring and supporting peer practice coordinators, opinions on the effectiveness of m-mentoring, confidence in their role as trainers, successes and challenges in collecting data was sought. Each IDI lasted about 45 minutes and was audio recorded.

\section{Training approach 2 and data collection: Traditional group training of participants - Group 2 or control group}

The traditional training approach consisted of eight days of lectures and practice sessions on simulators, offsite the participants' workplace, usually in a hotel. After obtaining consent, participants completed pretraining assessments consisting of MCQs and OSCEs; the latter were administered through use of anatomical models. The same modules offered to the LDHF/m-mentoting arm were offered and assed in the TRAD arm, 
all during the eight days training period. At the end of the eight-day training, the participants underwent an immediate post-training assessment, which included MCQs and OSCEs. As described in study arm 1, all questions answered correctly and procedure done competently were scored out of $100 \%$.

\section{Sample size}

The sample size was calculated as the average number of health workers who needed to be included from each of the 60 facilities (30 per study each arm) using a test of two proportions for a binary indicator of a present competency score. Competency was assumed at a score of $80 \%$ or higher on both the knowledge and skills assessments. We assumed that the proportion of competent providers would be $50 \%$ in the control group. The goal was to have at least $80 \%$ power to reject a null hypothesis that the proportions are equal across the two arms against the alternative hypothesis of a minimum effect size of 20 percentage point difference in proportions of competent providers. The test of hypothesis was performed at 0.05 level of significance. Sample size was calculated using PASS statistical software. Since some facility-level factors that are shared by the providers working in the same facility can influence competency level, we assumed 0.05 within facility correlation of competency levels across providers in each health facility. Assuming an average of four health workers sampled per health facility, a total of 240 providers across the two groups was needed so that there would be at least $80 \%$ power to detect a 20 percentage point difference in competence level between the two arms (assessment at 3 and 12 months) at 0.05 level of statistical significance. The final target sample size was 300 (or 150 providers per study arm) to account for potential $20 \%$ drop-out at the time of post-training assessment. More providers were to be recruited from Kogi State since it has a larger population than Ebonyi. Study participants recruited from each facility included the maternity unit head, wherever possible, and two others to ensure that the other team members received the necessary support to practice the competencies.

\section{Data analysis}

The primary outcome was health workers' clinical competency level in selected BEmONC skills at three months post-training assessed through simulation. The e secondary outcome was retention in clinical competency level in BEmONC skills as assessed through OSCEs and multiple choice knowledge questionnaires scores at 12 months post-training. The results presented in this article are based on assessments three and 12 months after training. For both arms, composite scores were computed for infection prevention, conduct of normal delivery, active management of the third stage of labor (AMTSL), neonatal resuscitation, case management of pre-eclampsia and eclampsia with magnesium sulphate (MgSO4) only, and management of primary postpartum hemorrhage (e.g., manual removal of placenta, internal bimanual uterine compression, and compression of the abdominal aorta). The composite scores calculated for each participant identified questions answered correctly and procedures done competently. The authors have published the analytical methods in a previous paper [5]. 
Descriptive analysis: Counts of absolute numbers and simple proportions were used to describe categorical variables. Measures of central tendency (mean and median) as well as dispersion (range and standard deviation (SD)) were also determined. Percentage of those achieving the required competency level $(\geq 80 \%$ post-training scores in multiple choice questionnaires and OSCE) in both study groups were computed.

Inferential analysis: A generalized linear model with robust facility-level variance was used to test the differences between arms on multiple choice knowledge questions and OSCE scores at 12 months using a group indicator as the main predictor in the model. Adjustment was made for health worker and facility-level characteristics that show imbalance between arms at baseline and can be strongly correlated with the outcome scores. A p-value $<0.05$ was considered statistically significant. In addition, we developed a longitudinal model that assessed the change in scores, aproxy for competency, over time post-training. This model is appropriate, since it accounts for correlations within a provider over time as well as within-facility correlations. Generalized linear population-average model estimates using generalized estimating equations with working exchangeable correlation structure were used.

Qualitative data, notes, and transcripts were entered into Atlas-ti version 8 software. All data were collected in English since the service providers have above basic level of education. Content analysis of the discussions was undertaken to generate themes of interest along which the analysis was done. The analytic process proceeded in two basic steps: using the thematic groups, emerging themes were summarized related to relevant specific objectives, and content was analyzed to compare the three different respondent groups across the two states.

\section{Results}

A total of 299 participants completed the study out of the original 323 providers who were randomized to different study arms; LDHF arm=172; TRAD arm=127 (Table 1 and Figure 1). Both arms had similar sociodemographic characteristics.

Table 2 shows that the TRAD arm had better knowledge test scores compared to the LDHF/m-mentoring arm at baseline and immediately after the training intervention in some thematic areas, such as AMTSL, essential newborn care, and neonatal resuscitation $(\mathrm{p}<0.05)$. However, at 3 and 12 months after training assessment, both arms are equal in knowledge acquisition and retention; no statistically significant differences were noted.

\section{Table 1: Baseline characteristics of study sample of providers by study arm}




\begin{tabular}{|c|c|c|c|}
\hline \multirow[t]{2}{*}{ Characteristic of Health Workers } & $\begin{array}{l}\text { LDHF/m- } \\
\text { mentoring }\end{array}$ & TRAD & \\
\hline & $\begin{array}{l}\mathrm{N}=172, \\
\text { Percent }\end{array}$ & $\begin{array}{l}\mathrm{N}=127, \\
\text { Percent }\end{array}$ & p value \\
\hline \multicolumn{4}{|l|}{ State or Location } \\
\hline Ebonyi & 36.6 & 26.0 & \multirow{2}{*}{$0.05^{a}$} \\
\hline Kogi & 63.4 & 74.0 & \\
\hline \multicolumn{4}{|l|}{ Type of Facility } \\
\hline Primary health center (PHC) & 38.4 & 47.2 & \multirow[t]{3}{*}{$0.05^{a}$} \\
\hline General/Mission hospital & 52.3 & 38.6 & \\
\hline Tertiary hospital & 9.3 & 14.2 & \\
\hline Mean (SD) Age: years & $41.0(10.3)$ & $40.6(8.8)$ & $0.78^{\mathrm{b}}$ \\
\hline \multicolumn{4}{|l|}{ Sex } \\
\hline Male & 15.7 & 22.0 & \multirow{2}{*}{$0.16^{\mathrm{a}}$} \\
\hline Female & 84.3 & 78.0 & \\
\hline \multicolumn{4}{|l|}{ Marital Status } \\
\hline Married & 84.3 & 89.0 & \multirow{4}{*}{$0.60^{\mathrm{C}}$} \\
\hline Single & 10.4 & 8.6 & \\
\hline Divorced & 0.6 & 0.0 & \\
\hline Widowed & 4.7 & 2.4 & \\
\hline \multicolumn{4}{|l|}{ Religion } \\
\hline Christian & 79.7 & 74.8 & \multirow{4}{*}{$0.33^{\mathrm{a}}$} \\
\hline Islam & 18.6 & 22.8 & \\
\hline Other & 0.0 & 0.8 & \\
\hline Missing & 1.7 & 1.6 & \\
\hline Duration Since Graduation: years & $\begin{array}{ll}12.0 & (6.0- \\
23.0)\end{array}$ & $\begin{array}{ll}14.0 & (8.0- \\
21.0)\end{array}$ & $0.54^{\mathrm{d}}$ \\
\hline \multicolumn{3}{|l|}{ Cadre/Job Title } & \multirow{5}{*}{$0.03^{c}$} \\
\hline Community health extension worker & 34.3 & 43.3 & \\
\hline Doctor & 3.5 & 8.7 & \\
\hline Nurse & 57.0 & 46.4 & \\
\hline Other & 5.2 & 1.6 & \\
\hline $\begin{array}{l}\text { Median (IQR) Duration Working at Facility since } \\
\text { Employment: years }\end{array}$ & $6.0(3.0-10.0)$ & $\begin{array}{ll}6.0 & (3.0- \\
10.0)\end{array}$ & $0.84^{\mathrm{d}}$ \\
\hline Median (IQR)* Time to Training: minutes & $\begin{array}{ll}60.0 & (60.0- \\
90.0) & \\
\end{array}$ & $\begin{array}{l}60.0 \quad(60.0- \\
120.0)\end{array}$ & $<0.001^{d}$ \\
\hline Duration at current position: median (IQR) years & $8.0(4.0-18.0)$ & $\begin{array}{ll}9.0 & (4.0- \\
15.0) & \end{array}$ & $0.76^{\mathrm{d}}$ \\
\hline
\end{tabular}

Types of tests: $a=$ Pearson's chi-squared; $b=$ Two sample $t$ test; $c=$ Fisher's exact; $d=$ Wilcoxon rank-sum. SD, standard deviation; IQR, interquartile range. ${ }^{*} T R A D$ participants residing within $5 \mathrm{~km}$ of the training sites were not accommodated in a hotel; they travelled daily to the training site. 
Table: 2: Comparison of levels of knowledge between study arms across four assessment periods 


\begin{tabular}{|c|c|c|c|c|c|c|c|c|}
\hline \multirow{3}{*}{$\begin{array}{l}\text { Thematic } \\
\text { Area \# }\end{array}$} & \multirow{3}{*}{$\begin{array}{l}\text { Thematic } \\
\text { Area }\end{array}$} & \multirow{3}{*}{$\begin{array}{l}\text { Total } \\
\text { number } \\
\text { of } \\
\text { items }\end{array}$} & \multicolumn{4}{|c|}{ Assessment 1-Baseline } & \multirow{2}{*}{\multicolumn{2}{|c|}{$\begin{array}{l}\text { Adjusted } \\
\text { analysis* }\end{array}$}} \\
\hline & & & & & \multicolumn{2}{|c|}{$\begin{array}{l}\text { Unadjusted } \\
\text { analysis }\end{array}$} & & \\
\hline & & & $\begin{array}{l}\text { Mean \# } \\
\text { correct, } \\
\text { LDHF }\end{array}$ & $\begin{array}{l}\text { Mean \# } \\
\text { correct, } \\
\text { TRAD }\end{array}$ & $\begin{array}{l}\text { IRR } \\
(95 \% \mathrm{CI})\end{array}$ & $p$ value & \begin{tabular}{l|} 
IRR \\
$(95 \% \mathrm{CI})$
\end{tabular} & p value \\
\hline 1 & $\begin{array}{l}\text { Infection } \\
\text { prevention }\end{array}$ & 6 & 3.17 & 2.67 & $\begin{array}{l}1.19 \\
(1.07 \\
1.32)\end{array}$ & 0.001 & $\begin{array}{l}1.17 \\
(1.06, \\
1.30)\end{array}$ & 0.002 \\
\hline 2 & Normal birth & 8 & 4.17 & 4.01 & $\begin{array}{l}1.04 \\
(0.96, \\
1.13)\end{array}$ & 0.349 & $\begin{array}{l}1.03 \\
(0.95 \\
1.12)\end{array}$ & 0.498 \\
\hline 3 & AMTSL & 4 & 1.79 & 1.73 & $\begin{array}{l}1.03 \\
(0.88 \\
1.21)\end{array}$ & 0.682 & $\begin{array}{l}1.02 \\
(0.88, \\
1.18)\end{array}$ & 0.822 \\
\hline 4 & $\begin{array}{l}\text { Management } \\
\text { of eclampsia }\end{array}$ & 2 & 1.13 & 1.11 & $\begin{array}{l}1.02 \\
(0.89, \\
1.18)\end{array}$ & 0.754 & $\begin{array}{l}1.02 \\
(0.88, \\
1.17) \\
\end{array}$ & 0.805 \\
\hline 5 & $\begin{array}{l}\text { Essential } \\
\text { newborn } \\
\text { care }\end{array}$ & 2 & 0.94 & 1.03 & $\begin{array}{l}.92 \\
(0.77 \\
1.09) \\
\end{array}$ & 0.318 & $\begin{array}{l}0.91 \\
(0.76, \\
1.08)\end{array}$ & 0.270 \\
\hline 6 & $\begin{array}{l}\text { Neonatal } \\
\text { resuscitation }\end{array}$ & 20 & 8.55 & 11.15 & $\begin{array}{l}0.77 \\
(0.70 \\
0.84)\end{array}$ & $<0.001$ & $\begin{array}{l}0.75 \\
(0.68 \\
0.82)\end{array}$ & $<0.001$ \\
\hline & Overall score & 42 & 17.62 & 19.71 & $\begin{array}{l}0.89 \\
(0.83 \\
0.96)\end{array}$ & 0.002 & $\begin{array}{l}0.88 \\
(0.82, \\
0.94)\end{array}$ & $<0.001$ \\
\hline \multirow[t]{3}{*}{$\begin{array}{l}\text { Thematic } \\
\text { Area \# }\end{array}$} & & \multirow{3}{*}{$\begin{array}{l}\text { Total } \\
\text { number } \\
\text { of } \\
\text { items }\end{array}$} & \multirow{2}{*}{\multicolumn{4}{|c|}{$\begin{array}{l}\text { Assessment } \\
\text { training }\end{array}$}} & & \\
\hline & & & & & & & \multicolumn{2}{|c|}{$\begin{array}{l}\text { Adjusted } \\
\text { analysis* }\end{array}$} \\
\hline & $\begin{array}{l}\text { Thematic } \\
\text { Area }\end{array}$ & & $\begin{array}{l}\text { Mean \# } \\
\text { correct, } \\
\text { LDHF }\end{array}$ & $\begin{array}{l}\text { Mean \# } \\
\text { correct, } \\
\text { TRAD }\end{array}$ & $\begin{array}{l}\text { IRR } \\
(95 \% \mathrm{CI})\end{array}$ & $p$ value & $\begin{array}{l}\text { IRR } \\
(95 \% C I)\end{array}$ & p value \\
\hline 1 & $\begin{array}{l}\text { Infection } \\
\text { prevention }\end{array}$ & 6 & 5.01 & 5.04 & $\begin{array}{l}1.00 \\
(0.94 \\
1.06)\end{array}$ & 0.888 & $\begin{array}{l}0.98 \\
(0.92, \\
1.04)\end{array}$ & 0.470 \\
\hline 2 & Normal birth & 8 & 6.51 & 6.76 & $\begin{array}{l}0.96 \\
(0.92 \\
1.01) \\
\end{array}$ & 0.134 & $\begin{array}{l}0.95 \\
(0.90 \\
1.00)\end{array}$ & 0.040 \\
\hline 3 & AMTSL & 4 & 3.2 & 3.49 & $\begin{array}{l}.92 \\
(0.86 \\
0.98)\end{array}$ & 0.009 & $\begin{array}{l}0.90 \\
(0.84 \\
0.96)\end{array}$ & 0.002 \\
\hline 4 & $\begin{array}{l}\text { Management } \\
\text { of eclampsia }\end{array}$ & 2 & 1.72 & 1.8 & $\begin{array}{l}0.95 \\
(0.89 \\
1.02) \\
\end{array}$ & 0.138 & $\begin{array}{l}0.95 \\
(0.89 \\
1.01) \\
\end{array}$ & 0.116 \\
\hline 5 & $\begin{array}{l}\text { Essential } \\
\text { newborn } \\
\text { care }\end{array}$ & 2 & 1.34 & 1.65 & $\begin{array}{l}0.81 \\
(0.74 \\
0.89)\end{array}$ & $<0.001$ & $\begin{array}{l}0.80 \\
(0.72, \\
0.88)\end{array}$ & $<0.001$ \\
\hline 6 & $\begin{array}{l}\text { Neonatal } \\
\text { resuscitation }\end{array}$ & 20 & 11.29 & 16.21 & $\begin{array}{l}0.7 \\
(0.63\end{array}$ & $<0.001$ & $\begin{array}{l}0.68 \\
(0.61\end{array}$ & $<0.001$ \\
\hline
\end{tabular}




\begin{tabular}{|c|c|c|c|c|c|c|c|c|}
\hline & & & & & $0.77)$ & & $0.75)$ & \\
\hline & Overall score & 42 & 24.21 & 30.57 & $\begin{array}{l}0.79 \\
(0.75, \\
0.84) \\
\end{array}$ & $<0.001$ & $\begin{array}{l}0.77 \\
(0.73, \\
0.82) \\
\end{array}$ & $<0.001$ \\
\hline \multirow[t]{3}{*}{$\begin{array}{l}\text { Thematic } \\
\text { Area \# }\end{array}$} & & \multirow{3}{*}{$\begin{array}{l}\text { Total } \\
\text { number } \\
\text { of } \\
\text { items }\end{array}$} & \multicolumn{4}{|c|}{$\begin{array}{l}\text { Assessment } \\
\text { training }\end{array}$} & & \\
\hline & & & & & \multicolumn{2}{|c|}{$\begin{array}{l}\text { Unadjusted } \\
\text { analysis }\end{array}$} & \multicolumn{2}{|c|}{$\begin{array}{l}\text { Adjusted } \\
\text { analysis* }\end{array}$} \\
\hline & $\begin{array}{l}\text { Thematic } \\
\text { Area }\end{array}$ & & $\begin{array}{l}\text { Mean \# } \\
\text { correct, } \\
\text { LDHF }\end{array}$ & $\begin{array}{l}\text { Mean \# } \\
\text { correct, } \\
\text { TRAD }\end{array}$ & \begin{tabular}{l|} 
IRR \\
$(95 \% \mathrm{CI})$
\end{tabular} & p value & \begin{tabular}{l|} 
IRR \\
$(95 \% \mathrm{CI})$
\end{tabular} & $p$ value \\
\hline 1 & $\begin{array}{l}\text { Infection } \\
\text { prevention }\end{array}$ & 6 & 4.54 & 4.24 & $\begin{array}{l}1.07 \\
(0.99, \\
1.16)\end{array}$ & 0.086 & $\begin{array}{l}1.04 \\
(0.96, \\
1.12)\end{array}$ & 0.348 \\
\hline 2 & Normal Birth & 8 & 5.9 & 5.7 & $\begin{array}{l}1.04 \\
(0.96, \\
1.11)\end{array}$ & 0.342 & $\begin{array}{l}1.01 \\
(0.94, \\
1.08)\end{array}$ & 0.760 \\
\hline 3 & AMTSL & 4 & 3.07 & 3.04 & $\begin{array}{l}1.01 \\
(0.92, \\
1.10)\end{array}$ & 0.853 & $\begin{array}{l}0.97 \\
(0.89, \\
1.06)\end{array}$ & 0.569 \\
\hline 4 & $\begin{array}{l}\text { Management } \\
\text { of Eclampsia }\end{array}$ & 2 & 1.69 & 1.7 & $\begin{array}{l}1.00 \\
(0.92, \\
1.08)\end{array}$ & 0.932 & $\begin{array}{l}0.99 \\
(0.91, \\
1.07)\end{array}$ & 0.741 \\
\hline 5 & $\begin{array}{l}\text { Essential } \\
\text { Newborn } \\
\text { Care }\end{array}$ & 2 & 1.55 & 1.52 & $\begin{array}{l}1.02 \\
(0.91, \\
1.14)\end{array}$ & 0.781 & $\begin{array}{l}1.00 \\
(0.89, \\
1.12)\end{array}$ & 0.964 \\
\hline \multirow[t]{2}{*}{6} & $\begin{array}{l}\text { Neonatal } \\
\text { Resuscitation }\end{array}$ & 20 & 14.45 & 13.98 & $\begin{array}{l}1.03 \\
(0.96, \\
1.11) \\
\end{array}$ & 0.372 & $\begin{array}{l}1.00 \\
(0.93, \\
1.08) \\
\end{array}$ & 0.978 \\
\hline & Overall score & 42 & 27.41 & 26.37 & $\begin{array}{l}1.04 \\
(0.98, \\
1.10)\end{array}$ & 0.200 & $\begin{array}{l}1.01 \\
(0.95, \\
1.06)\end{array}$ & 0.796 \\
\hline \multirow[t]{3}{*}{$\begin{array}{l}\text { Thematic } \\
\text { Area \# }\end{array}$} & & \multirow{3}{*}{$\begin{array}{l}\text { Total } \\
\text { number } \\
\text { of } \\
\text { items }\end{array}$} & \multicolumn{4}{|c|}{$\begin{array}{l}\text { Assessment 4-12 months post- } \\
\text { training }\end{array}$} & & \\
\hline & & & & & \multicolumn{2}{|c|}{$\begin{array}{l}\text { Unadjusted } \\
\text { analysis }\end{array}$} & \multicolumn{2}{|c|}{$\begin{array}{l}\text { Adjusted } \\
\text { analysis* }\end{array}$} \\
\hline & $\begin{array}{l}\text { Thematic } \\
\text { Area }\end{array}$ & & $\begin{array}{l}\text { Mean \# } \\
\text { correct, } \\
\text { LDHF }\end{array}$ & $\begin{array}{l}\text { Mean \# } \\
\text { correct, } \\
\text { TRAD }\end{array}$ & \begin{tabular}{l|} 
IRR \\
$(95 \% \mathrm{CI})$
\end{tabular} & $p$ value & \begin{tabular}{l|} 
IRR \\
$(95 \% C I)$
\end{tabular} & p value \\
\hline 1 & $\begin{array}{l}\text { Infection } \\
\text { prevention }\end{array}$ & 6 & 4.15 & 3.99 & $\begin{array}{l}1.04 \\
(0.95, \\
1.14)\end{array}$ & 0.380 & $\begin{array}{l}1.01 \\
(0.93, \\
1.10)\end{array}$ & 0.795 \\
\hline 2 & Normal birth & 8 & 5.59 & 5.32 & $\begin{array}{l}1.05 \\
(0.97, \\
1.14)\end{array}$ & 0.213 & $\begin{array}{l}1.03 \\
(.95 \\
1.11)\end{array}$ & 0.470 \\
\hline 3 & AMTSL & 4 & 2.88 & 2.89 & $\begin{array}{l}1.00 \\
(0.90, \\
1.10) \\
\end{array}$ & 0.944 & $\begin{array}{l}0.96 \\
(0.88, \\
1.06) \\
\end{array}$ & 0.426 \\
\hline 4 & $\begin{array}{l}\text { Management } \\
\text { of eclampsia }\end{array}$ & 2 & 1.61 & 1.59 & $\begin{array}{l}1.02 \\
(0.93\end{array}$ & 0.730 & $\begin{array}{l}1.00 \\
(0.92\end{array}$ & 0.920 \\
\hline
\end{tabular}




\begin{tabular}{|l|l|l|l|l|l|l|l|l|} 
& & & & $1.11)$ & & $1.10)$ & \\
\hline $\mathbf{5}$ & Essential & 2 & 1.51 & 1.46 & $\begin{array}{l}1.04 \\
(0.93,\end{array}$ & 0.544 & 1.01 & 0.867 \\
& newborn & & & & 0.90, & \\
& care & & & & $1.16)$ & & $1.13)$ & \\
\hline $\mathbf{6}$ & Neonatal & 20 & 13.83 & 14.02 & 0.99 & 0.588 & 0.95 & $\mathbf{0} 036$ \\
& resuscitation & & & & $(0.94$, & & $(0.91$, & \\
& & & & $1.04)$ & & $1.00)$ & \\
\hline & Overall score & 42 & 26.47 & 26.16 & 1.01 & 0.642 & 0.98 & 0.340 \\
& & & & & $(0.96$, & & $(0.94$, & \\
& & & & & $1.06)$ & & $1.02)$ & \\
\hline
\end{tabular}

$I R R$, incidence rate ratio; CI, Confidence interval

\section{Comparison of Skills Competency Scores}

Health workers in both arms showed improvement in overall pass rates in clinical skills competency, improving from around $30 \%$ at baseline to $75 \%$ and above at endline; difference-in-differences were statistically significant ( $p<0.05$ ); TRAD (from $27.4 \%$ to $74.8 \%$ ) and LDHF/m-mentoring (from $30.1 \%$ to $81.1 \%$ ). Overall, the observed improvement and retention of BEmONC skills was higher in LDHF/m-mentoring study arm participants $(81.1 \%)$ compared to the TRAD arm participants $(74.8 \%)$ at 12 months post-training $(\mathrm{p}<0.05)$. There was a dip in both arms at the three-month assessment. (Figure 2 )

Figure 3 shows that overall for BEmONC skills, the LDHF/m-mentoring arms had better post-training assessment scores at 12 months post-training for assisting normal birth (including care of the newborn), AMTSL, manual removal of placenta, bimanual compression of the uterus, abdominal aortic compression, pre-eclampsia/eclampsia management $(p<0.05)$.

\section{Provider Perspectives on the LDHF/m-mentoring approach}

A total of 40 IDIs were conducted among 20 peer practice coordinators, 14 master mentors, four health facility managers, two ministry of health officers. In addition, six FGDs comprising eight to 10 participants each who were selected from among the trainees at 12 months post-training. During the qualitative data collection, some participants commented in favor of the LDHF approach to capacity building. Some noted that the support provided by master mentors via phone facilitated the approach. One of the mentors reported that the support provided helped solve challenges:

"Occasionally they call me when they have difficulty in the hospital, I also assist them. On phone, I discussed topics such as normal delivery, administration of magnesium sulphate and manual removal of placenta.'[Mentor, $\mathrm{HOH}]$

Although per-diem payments were not provided, some respondents reported that the refreshments provided made it easier to participate in the LDHF/m-mentoring approach. One mentor opined that:

"I motivate them by giving them little things (lunch) just to encourage them, yes, light refreshment during practice." [Mentor, $\mathrm{MOH}]$

It is also perceived that monitoring and evaluation through text messages and quizzes enhanced the LDHF/mmentoring approach. When asked what they thought about the reminders and quizzes, a health worker said 
that,

"It made us practice. And any procedure we did not get right was corrected immediately."[Service Provider]

Respondents were also perceived that there was improved newborn/neonatal survival due to acquired skills, which motivated the participants to practice more. One participant said:

"Firstly, since the training, we have not had maternal or neonatal deaths in our facility, especially in newborn resuscitation. We have saved babies that would have died." [Service Provider]

Providers also shared some challenges to implementing the LDHF/m-mentoring approach. Lack of funding resulted in reduced frequency of $\mathrm{m}$-mentoring sessions. The use of mobile phones requires payment for airtime and internet costs, which may not be available when required. One mentor said:

"Initially, I was making frequent calls, but later it was reduced to twice every month. I have not been paid for what I have spent so far in making calls to peer practice coordinators." [Mentor, $\mathrm{MOH}$ ]

Conflicting work schedules made it difficult to get everyone to practice the skills on the anatomic models at the same time. A peer practice coordinator said:

"It was very difficult to get members of the group to come together to practice due to our work schedule." [PPC, health facility]

Workloads and the need to attend to other issues within the hospital prolonged peer practice sessions. One respondent said:

"There was the problem of so much distraction because the people were busy in the ward. You keep starting afresh when they go out and come back. So it took time to complete the tasks listed in the tools." [Service Provider]

Labor strikes by health workers made it difficult for regular peer practice sessions to take place and made it even more difficult to translate knowledge to actual practice. One respondent said:

"Frequent strikes has seriously hindered our being able to translate knowledge to practice." [Service Provider]

\section{Discussion}

In this cluster randomized control trial, the knowledge assessment scores increase from baseline to endline at 12 months between the study arms, but the acquisition and retention of BEmONC skills was different at 12 months with the LDHF/m-mentoring arm demonstrating better performance than the TRAD arm. This study contributes to the much needed evidence base for LDHF/m-mentoring training approach in LMICs, adding on the finding of related studies done in Uganda [1] and Ghana [2]. As part of the intervention package, LDHF/mmentoring study arm participants received weekly SMS reminders and quizzes along with continuous skills practice on anatomical models, which helped, reinforce knowledge on specific clinical areas over time. In contrast, the TRAD arm participants, which represent the status-quo, did not have the extra support, which might explain the differences in skills performance at 12 months. Furthermore, information gathered 
qualitatively suggests that a key benefit of $m$-mentoring is the ability of trainees to call their mentors at the point of care to address uncommon complications such as placenta praevia. This close mentor-mentee relationship might also have helped the mentees to develop confidence in these crucial skills, which demonstrates a great potential of the LDHF/m-mentoring approach.

Overall, the LDHF arm had better skills performance at all the assessment points compared to the TRAD arm. Of note, there was an observed drop in skills competency at three months in both arms from the immediate post-training assessment. Some of the possible explanation for the drop in skills competency is that it takes time following intense training, before a practice has been established as routine. Another possible cause for the drop may have been that there was a health workers' strike that was ongoing just before the post-training assessments in the two states. Despite these factors, the LDHF/m-mentoring arm still performed better in all competencies at 3-and 12- months post-training. It's encouraging to note that this observed better performance was in competences that are very crucial for the survival of the mother and the baby on the day of birth; these include, AMTSL, manual removal of placenta, neonatal resuscitation, loading dose of magnesium sulphate, and pre-eclampsia/eclampsia. The continued simulation practice may have helped in building and retaining these competencies.

Studies on BEmONC in-service training have demonstrated the value of simulation and continuous practice in improving knowledge and skills competency $[1,2,7]$. This has led to adaptation of various approaches to determine which ones lead to the greatest returns on investment [1-4, 8-11]. Our findings are consistent with those of previous studies that reported TRAD offsite training may improve the trainees' competencies, but knowledge and skills may not be transferred to other co-workers at the facility, nor translated into practice or performance [12,13]. On the other hand, methods that involve repetitive, mentor-supported learning and regularly coordinated practice sessions, such as the onsite LDHF/m-mentoring training, result in better skills acquisition and retention over time [1,2,5,7,14-17]. This claim has been supported by other rigorously, welldesigned studies that showed that onsite LDHF/m-mentoring training approach, coupled with an efficient mentorship program, resulted in improved provider preparedness to deal with complications $[1,2,15]$.

Findings from the Ghana study [2] that measured patient-level outcomes showed that the LDHF/m-mentoring training approach was associated with a sustained decrease in facility-based newborn mortality and intrapartum stillbirths [2]. The limitations acknowledged by Gomez and colleagues in the Ghana study, such as the lack of a randomized control trial design and lack of concealment/information bias, have been addressed in our study using a cluster randomized controlled trial in a similar low-resource setting. Although our study did not measure patient-level outcomes, we assessed a crucial component of the day of birth, namely the competency of the service providers. Our study was adequately powered to produce generalizable conclusions on the comparative effectiveness of the LDHF/m-mentoring and TRAD approaches in the study setting and possibly in similar environments especially in LMICs. As reported by other studies, to be effective, training programs should be conducted as close as possible to the workplace and be competency-based [1618].

The present study also adds to the growing yet still insufficient body of evidence in LMICs supporting the use of simulation, specifically for training in the management of obstetrics and newborn emergencies [19-21]. Skills that are not used very frequently, such as management of obstetric and newborn complications, are

Page 16/23 
likely to be non-existent or lost due to a lack of use, and therefore the need to practice often. The appropriate dose or frequency of practice in order to reach competency level depends on many factors, which may include the personal attributes of service provider among other things. Simulation-based trainings provide participants with the opportunity to repeat practice sessions in a safe environment where they will not harm patients [1-2, $18,21]$. Using the workplace to practice skills is beneficial. The availability of the anatomical models for continuous onsite simulation practice sessions also helps to organize emergency drills to test the health systems response to life-threatening complications.

Another important finding is that some of the enablers for the LDHF/m-mentoring approach are related to successful outcomes that were reported as health workers improved their skills, which motivated the participants to practice more and seek support from master mentors. On the other hand, some of the barriers to this approach include logistics, such as availability of space for the practice sections and labor strikes by health workers. It has been reported that inadequate mentorship should be addressed to improve quality of BEmONC [22]. To function maximally, health workers need to improve their competency and they need an enabling environment, including availability of supplies, equipment, appropriate guidelines and policies, and timely remuneration $[23,24]$. Our study findings corroborated those of previous studies in LMICs on the effectiveness of the LDHF training approach compared to the offsite traditional training approach to build health workers capacity $[1,2]$.

This study had some limitations some of which have been reported through the qualitative data presented as challenges and barriers experienced. These include some operational-level logistical challenges in ensuring that the mentors always had the airtime in a timely manner in order to maintain seamless communication with the mentees. The was mitigated by the mentors being very understanding by using their resources as they awaited support provided through the study. Another limitation was the health workers' strike which occurred around month three post-training, which potentially affected the findings negatively at that assessment period. Finally, although the study team had lobbied the MOH not to transfer the participants to other non-study facilities for duration of the study, some staff were transferred. However, the proportion was very low; they were not included in the analysis.

\section{Conclusion}

This is one of the few studies from a middle-income country that has used a pragmatic design-a cluster randomized controlled trial and qualitative methods-to generate much needed information on learning outcomes of two approaches to health worker capacity building. Our study findings corroborate those of similar studies that used rigorous methodology, to support the proposition to a shift from traditional offsite group-based training to low-dose, high-frequency and onsite training as an effective way to build the capacity of maternal and newborn care providers. This shift can be explored in other clinical settings to improve the quality of care. The findings suggest that a low-dose, high frequency and simulation- and practice-based training approach, including mobile mentoring is likely to result in better skills competency outcomes and higher skills retention among health workers. This study has shown promising results that can address health worker absenteeism due to frequent offsite trainings, which are a major concern for health facility managers in LMICs. Training staff onsite without taking them away from service delivery points is a strong reason for adoption of the LDHF/m-mentoring approach.

Page 17/23 
The findings are expected to provide health facility managers and other decision makers with valuable information to guide resource allocation for maximum benefit and effectiveness in building the capacity of frontline health workers. The authors recommend that capacity building among healthcare workers, to the extent possible, should utilize the onsite LDHF/m-mentoring learning approach. Further evidence is needed to determine the value of m-mentoring in influencing learning outcomes and the cost-effectiveness of both training approaches as these were not explored in our study.

\section{List Of Abbreviations}

AMTSL: Active management of third stage of labor

BEmONC: basic emergency obstetric and newborn care

IQR: interquartile range

LDHF: low-dose, high-frequency; m-mentoring: mobile mentoring

$\mathrm{MOH}$; Ministry of Health

OSCE: objective structured clinical examination

SD: standard deviation

TRAD: traditional group-based training.

\section{Declarations}

\section{Ethics approval and consent to participate}

Ethical approval was obtained from Nigerian Health Research Ethics Committee with approval number NHREC/ 01/01/2007 November 2015 and the Johns Hopkins School of Public Health, Institutional Review Board \#000007196, on August 23rd, 2016. The trial was retrospectively registered with the NIH-Sponsored ClinicalTrials.Gov registry on 24th August, 2017: NCT03269240. Verbal informed consent was obtained from study participants and confidentiality was assured. Verbal informed consent was used because the authors thought that asking health providers to review and sign forms might be considered risky because of the fear that if they performed poorly their supervisors may see their scores and trace it back to them.

\section{Consent for publication}

Not applicable

\section{Availability of data and material}

The datasets generated and/or analyzed during the current study are available in the figshare repository, https://doi.org/10.6084/m9.figshare.9955133 


\section{Competing interests}

The authors declare that they have no competing interest.

\section{Funding}

This study was made possible by the generous support of the American people through the United States Agency for International Development (USAID) under the terms of the Cooperative Agreement AID-OAA-A-1400028. The contents are the responsibility of the authors and do not necessarily reflect the views of USAID or the United States Government. The USAID contributed to the design of the study by improving the methodology rigor and also reviewed the final manuscript.

\section{Authors' contributions}

EU, MK, EO, GY, AO, BO1, UO, JE, GI, GA, GO, OA, CO, AA and BO2 contributed to the data collection, analysis and development of the manuscript. EU, MK, EO and GY conceived the idea of the manuscript and wrote the initial draft. All other authors contributed significantly to the research project and manuscript development. All authors read and approved the final manuscript.

\section{Acknowledgements}

The authors acknowledge the support received from the Federal Ministry of Health, Ebonyi State Ministry of Health and Kogi State Ministry of Health, Nigeria, health providers in the all the selected health facilities during the design and implementation stages. We also acknowledge and sincerely thank Elizabeth Thompson, Barbara Rawlins and Jennifer Hoeg for reviewing the manuscript and making very valuable corrections and Edward Bunker for support in data de-identification.

\section{Authors' Information}

1Jhpiego-an affiliate of Johns Hopkins University, 971 Reuben Okoya Crescent, Wuye District, Abuja, Nigeria.

${ }^{2}$ Jhpiego-an affiliate of Johns Hopkins University, 1615 Thames St, Baltimore, MD 21231, USA. ${ }^{3}$ The Johns Hopkins Biostatistics Center, Johns Hopkins Bloomberg School of Public Health, 615 N. Wolfe Street, Baltimore, MD 21205, ${ }^{4}$ Department of Public Health, State Ministry of Health, Lokoja, Kogi State, Nigeria,

${ }^{5}$ Department of Public Health, State Ministry of Health, Abakiliki, Ebonyi State, Nigeria

\section{Additional file}

None

\section{References}

1. Evans CL, Bazant E, Atukunda I, Williams E, Niermeyer S, Hiner C, et al. Peer-assisted learning after onsite, low-dose, high-frequency training and practice on simulators to prevent and treat postpartum hemorrhage and neonatal asphyxia: A pragmatic trial in 12 districts in Uganda. PLoS ONE. 2018; doi.org/10.1371/journal.pone.0207909 
2. Gomez PP, Nelson AR, Asiedu A, Addo E, Agbodza D, Allen C, et al. Accelerating newborn survival in Ghana through a low-dose, high-frequency health worker training approach: a cluster randomized trial. BMC Pregnancy Childbirth. 2018; doi:10.1186/s12884-018-1705-5.

3. Leslie HH, Gage A, Nsona H, Hirschhorn LR, Kruk ME. Training and supervision did not meaningfully improve quality of care for pregnant women or sick children in Sub-Saharan Africa. Health Aff (Millwood). 2016; doi.org/10.1377/hlthaff.2016.0261.

4. Gulmezoglu AM, Lawrie TA. Impact of training on emergency resuscitation skills: Impact on Millennium Development Goals (MDGs) 4 and 5. Best Pract Res Clin Obstet Gynaecol. 2015; doi.org/10.1016/j.bpobgyn.2015.03.018.

5. Ugwa E, Otolorin E, Kabue M, Ishola G, Evans C, Oniyire A, et al. Simulation-based low-dose, highfrequency plus mobile mentoring versus traditional group-based training approaches on day of birth care among maternal and newborn healthcare providers in Ebonyi and Kogi States, Nigeria; a randomized controlled trial. BMC Health Serv Res. 2018;18:630.

6. Nkwo PO, Lawani LO, Ubesie AC, Onodugo VA, Obu HA, Chinawa JM. Poor availability of skilled birth attendants in Nigeria: A case study of Enugu state primary health care system. Ann Med Health Sci Res. 2015;5:20-5.

7. Bluestone J, Johnson P, Fullerton J, Carr C, Alderman J, BonTempo J. Effective in-service training design and delivery: evidence from an integrated literature review. Hum Resour Health. 2013; 11:51.

8. Banke-Thomas A, Wilson-Jones M, Madaj B, van den Broek N. Economic evaluation of emergency obstetric care training: a systematic review. BMC Pregnancy Childbirth. 2017; doi: 10.1186/s12884-0171586-z.

9. Frank K, Lombaard H, Pattinson R. Does completion of the essential steps in managing obstetric emergencies (ESMOE) training package result in improved knowledge and skills in managing obstetric emergencies? South African J Obstet. 2009;15:94-9.

10. Ameh CA, van den Broek N. Making it happen: training health-care providers in emergency obstetric and newborn care. Best Pract Res Clin Obstet Gynaecol. 2015;29:1077-91.

11. Shoushtarian M, Barnett M, McMahon F, Ferris J. Impact of introducing practical obstetric multiprofessional training (PROMPT) into maternity units in Victoria, Australia. BJOG. 2014;121:1710-8.

12. Evans CL, Bazant E, Johnson P, Hiner C, Williams E, Conecker G, et al. Saving Lives at Birth Final Report: Building and Sustaining Capacity of Frontline Health Workers in Uganda. Baltimore: A partnership of: Jhpiego, USAID, Norwegian Ministry of Foreign Affairs; Bill \& Melinda Gates Foundation; Grand Challenges Canada; UKaid; American Academy of Pediatrics; Laerdal; 2016.

13. Evans CL, Johnson P, Bazant E, Bhatnagar N, Zgambo J, Khamis AR. Competency-based training Helping Mothers Survive: Bleeding after Birth for providers from central and remote facilities in three countries. Int. J. Gynecol. Obstet. 2014; doi.org/10.1016/j.ijgo.2014.02.021.

14. Otolorin E, Gomez P, Currie S, Thapa K, Dao B. Essential basic and emergency obstetric and newborn care: From education and training to service delivery and quality of care. Int. J. Gynecol. Obstet. 2015;130:S46-S53.

15. Sutton RM, Niles D, Meaney P, Aplenc R, French B, Abella BS, et al. Low-dose, high-frequency CPR training improves skill retention of in-hospital pediatric providers. Pediatrics 2011;128:e145-e151. 
16. Jayanna K, Bradley J, Mony P, Cunningham T, Washington M, Bhat S, et al. Effectiveness of Onsite Nurse Mentoring in Improving Quality of Institutional Births in the Primary Health Centres of High Priority Districts of Karnataka, South India: A Cluster Randomized Trial. PLoS ONE 2016; doi:10.1371/journal.pone.0161957.

17. Ameh CA, Broek N. Making It Happen: Training health-care providers in emergency obstetric and newborn care. Best Pract Res Clin Obstet Gynaecol 2015; 29 (8):1077-1091.

18. Ameh CA, Kerr R, Madaj B, Mdegela M, Kana T, Jones S, et al. Knowledge and skills of healthcare providers in Sub-Saharan Africa and Asia before and after competency-based training in emergency obstetric and early newborn care. PLoS ONE. 2016; doi:10.1371/journal.pone.0167270.

19. Lentz GM, Mandel LS, Lee D, Gardella C, Melville J, Goff BA. Testing surgical skills of obstetric and gynecologic residents in a bench laboratory setting: validity and reliability. Am J Obstet Gynecol. 2001; 184, 1462-1468, discussion 1468-70.

20. Macedonia, CR, Gherman, RB, Satin AJ. Simulation laboratories for training in obstetrics and gynecology. Obstet Gynecol. 2003; 102, 388-392.

21. Meri en, AER., van de Ven J, Mol BW, Houterman S, Oei SG. Multidisciplinary team training in a simulation setting for acute obstetric emergencies: A systematic review. Obstet Gynecol. 2010; doi.org/10.1097/AOG.0b013e3181d9f4cd.

22. Amatullah AF. Using interprofessional simulation-based training to improve management of obstetric emergencies: A systematic review. Clinical Simulation Nursing. 2018; doi.org/10.1016/j.ecns.2017.10.014.

23. Austin A, Gulema H, Belizan M. Barriers to providing quality emergency obstetric care in Addis Ababa, Ethiopia: Healthcare providers' perspectives on training, referrals and supervision, a mixed methods study. BMC Pregnancy Childbirth. 2015;15(1):1.

24. Graham W, Bell J, Bullough C. Can skilled attendance at delivery reduce maternal mortality in developing countries? In: De Brouwere V, van Lerberghe W, editors. Safe motherhood strategies: a review of the evidence. Antwerp, ITGPress, 2001, 97-129.

\section{Figures}




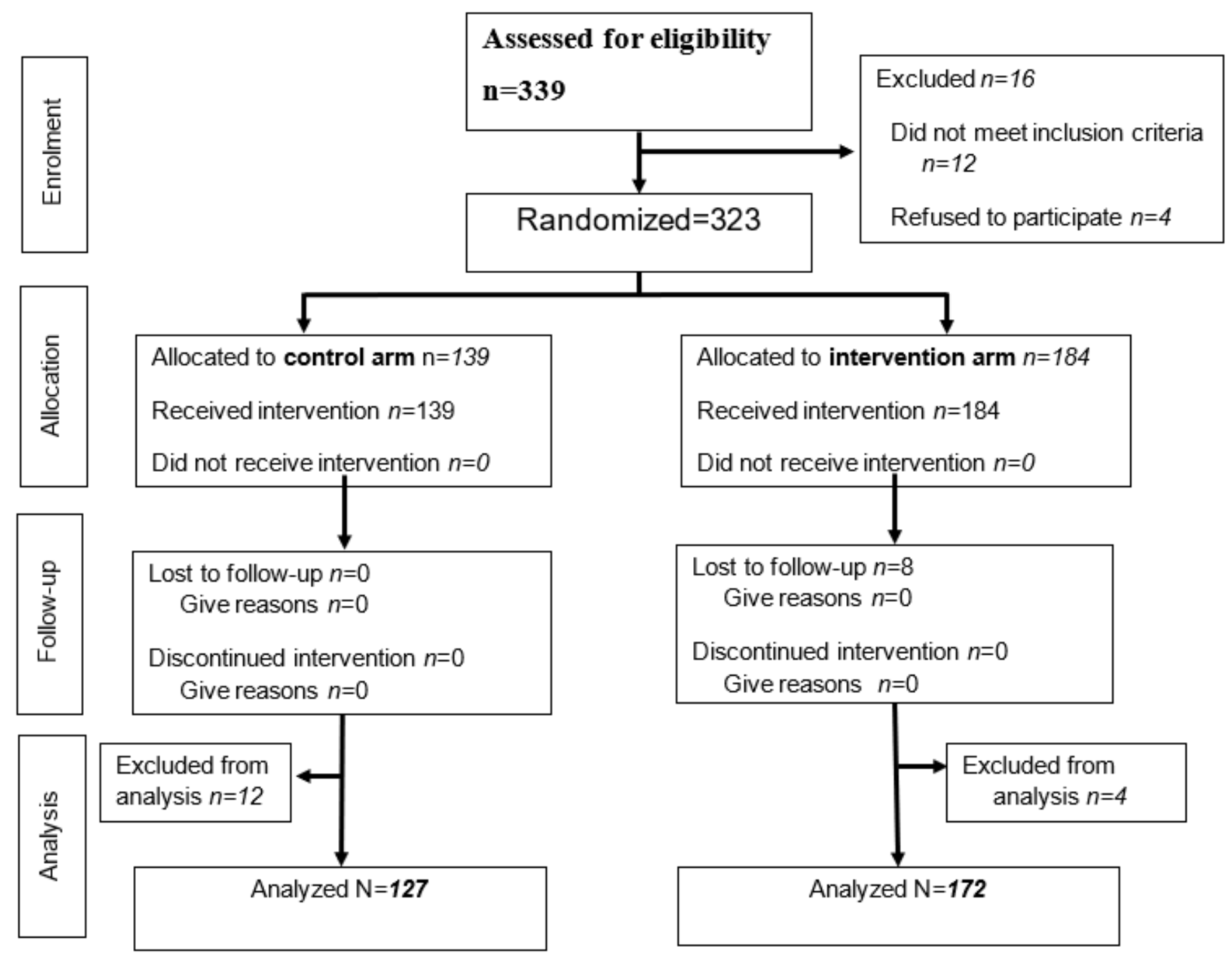

Figure 1

Consort flowchart of enrolment of study participants and data analysis 


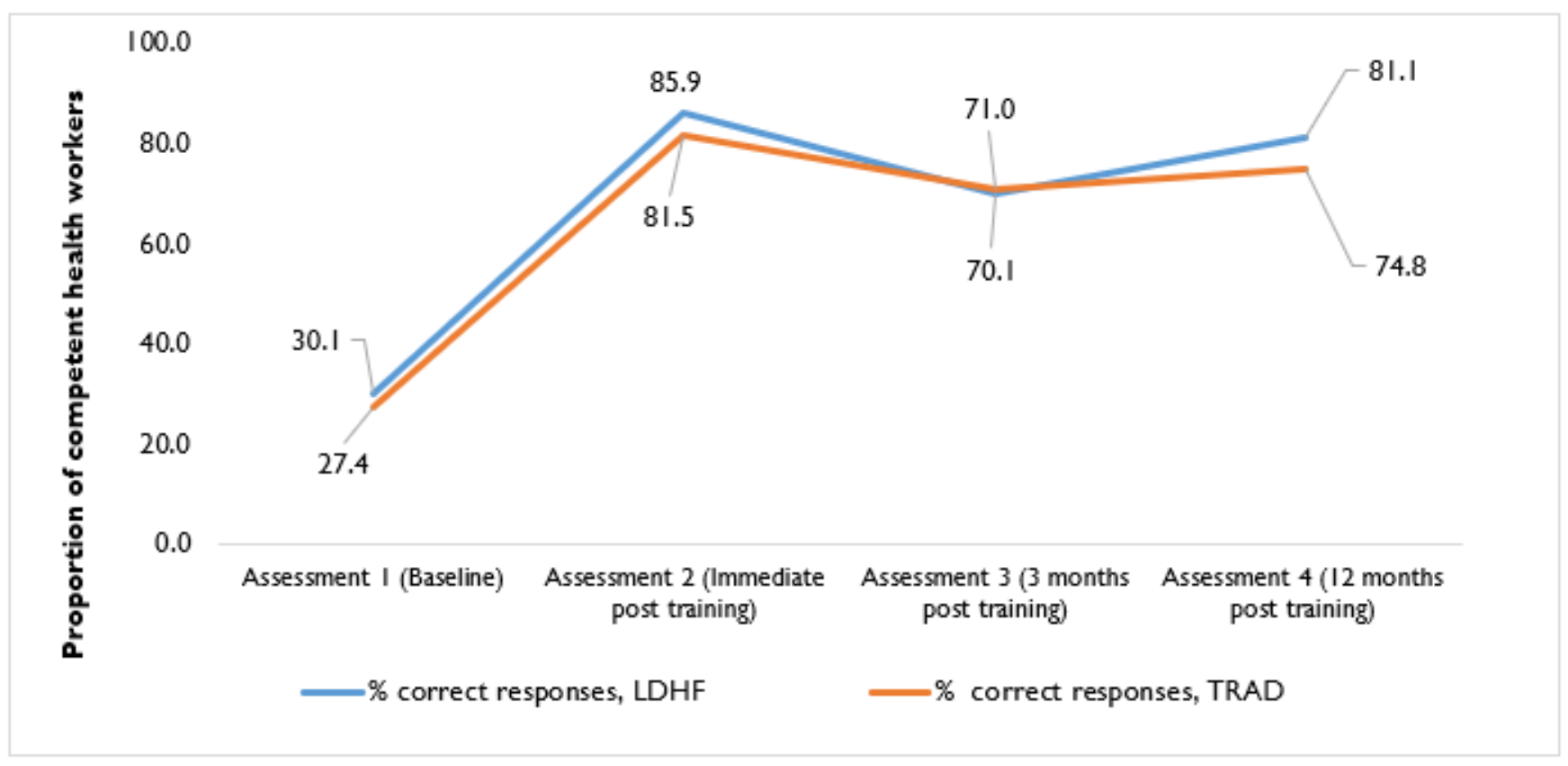

Figure 2

Trends in BEmONC skills mean composite scores by study arm over 12-month period

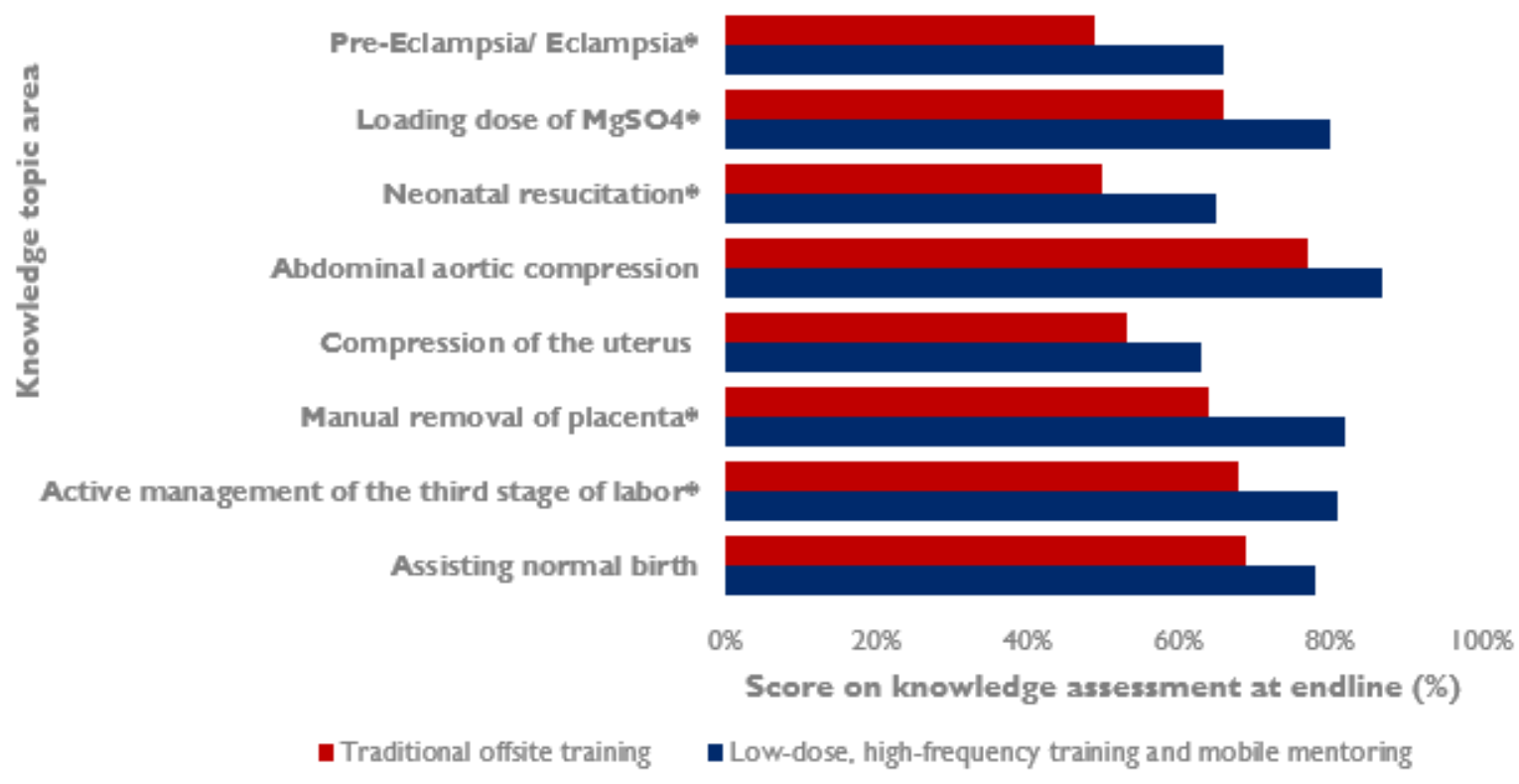

*denotes $p$ value $<0.05$

Figure 3

Assessment of providers' BEmONC skills at 12 months post-training 